\title{
To improve work force productivity in a medium size manufacturing enterprise by MOST Technique
}

\author{
Mr. Pramandra Kumar Gupta ${ }^{1}$, Mr Saurabh Singh Chandrawat ${ }^{2}$ \\ ${ }^{1}$ Lecturer mechanical Engineering, Govt.Polytechnic College,Kota(Rajasthan),India. \\ 2. HOD Mechanical Engineering Mewar University,Chittorgarh(Raj.)India.
}

\begin{abstract}
Competitive market is forcing big organizations to utilize the untapped potential of Medium Size Manufacturing Enterprises (MSME). Lean manufacturing system (LMS) is characterized by reduced product development and manufacturing lead-time, team based work organizations, low setup/changeover times, multifunctional workers and JIT deliveries from few reliable suppliers. Effective utilization of workforce is a primary objective for any manufacturing organization is no exception to this. In-fact, considering the significant environmental and safety risks associated, it becomes imperative to deploy the right number of associates in the plant and at appropriate locations. MOST (Maynard Operation Sequence Technique) is a work measurement technique developed by H. B. Maynard and Company, Inc. in the Unites States. MOST has been already introduced into the wide varieties of industries, such as aerospace, automotive, electronics, etc., in EU, US, and Asia. MOST is a work measurement system which can be easily implemented and practically maintained. *MOST is a registered trademark of H. B. Maynard and Company, Inc.
\end{abstract}

Keywords-LEMW (Lean Enterprises MOST Way), LMS (Lean Manufacturing System), MOST (Maynard Operation Sequence Technique), MDAT (MOST Application Data Acquisition Tools), MSME (Medium size Manufacturing Enterprise), TMU (Time Measurement Unit), Productivity.

\section{Introduction}

The term lean describes Japanese systems, which comparative to mass production uses fewer resources to achieve the output, which is better in terms of quality and satisfy the needs of customers. . LMS culture is based on working in every facet of the value stream by identifying and eliminating the waste. Waste in Japan as defined by Toyota's Fujio Cho is "any thing other than the minimum amount of equipment, materials, parts and workers (working time) which are absolutely essential to production. Typical forms of waste are defects, rework, setup, inventory, waiting, transport etc. LMS as a manufacturing philosophy can help MSMEs to identify and eliminate waste, making their processes flexible and reliable and align them to the requirements of their customers. With technology up-gradation, value addition techniques, credit support and export marketing zones, MSMEs can increase their share in exports also.

The LMS changes how people work. For most people, this will mean more challenging jobs, greater responsibilities and team working rather than narrow professional careers.

MOST,including the Basic, Mini, and Maxi versions, makes the measurement of work a practical, efficient, and inexpensive task for the industrial engineer. A powerful analytical tool that helps increase productivity, improve methods, facilitate planning, establish workloads, estimate labor costs, improve safety, and maximize resources, MOST can be applied to any type of work for which a method can be defined and described. Because of its universal applicability, MOST has become the standard for thousands of companies in a broad range of industries. In fact, there are now approximately 25,000 certified MOST applicators in the United States, Japan, and at least 30 other countries. User-friendly and easy to learn, MOST has been accepted by countless industries as one of the most efficient work measurement techniques available. In addition, a majority of the colleges and universities that teach industrial engineering now include an appreciation of MOST in their curricula because

1. Reduces the costs and paperwork and improves productivity.

2. Streamlines operations and quickly identifies inefficient methods.

3. Provides consistent standards and accuracy to within $\pm 5 \%$ with a $95 \%$ confidence level.

4. Can be applied to any method-defined manual work.

5. Reduces the time required for data development and standard setting.

6. Is easy to learn and use; even non-Industrial Engineers require little training. 


\section{Literature Review}

The key feature of Lean Manufacturing System is that fewer resources inputs are required by the manufacturing system (less material, fewer parts, shorter production operations, less unproductive time needed to setup etc.) At the same time there is a pressure for higher output performance to be achieved (better quality, higher technical specifications, greater product variety etc) [1]. This paper discusses importance of Lean manufacturing philosophy, its tools and techniques and implantation at a MSME to improve its effectiveness and efficiency through a Indian case.

\subsection{Mediumssize industries \& LMS}

In India the MSMEs are producing more than 8000 components and consist of Traditional Cottage \& house hold Industries and modern small scale Industries .The growth in MSMEs sector will promote:

- More employment opportunities in rural areas.

- Development of entrepreneurship.

- Production of Bio and agro products.

- Reduced regional imbalances.

- Stronger supply chains.

- Availability of competitive products at faster pace.

To get these benefits for the society from MSMEs it is necessary to improve their operational system. The Manufacturing System in MSMEs are generally consists of obsolete technology, low reliability, high changeover time, low flexibility, high employee turnover, less skilled and demotivated workforce. These organizations also lack in managerial skills for Quality Management, Inventory Management and Production Planning \& Control. These factors result in high cost, inferior quality, high rejection and rework, and poor delivery performance. For sustainable growth the organization must adopt introduction of innovative products/ processes, quality \& productivity improvement techniques, and effective technology management and establish a performance measurement system to assess the improvements achieved. [2] presented a framework for MSMEs network-level performance measurement system. The MSMEs network assessed based on network culture, resources and competences, models of actions, internal processes, customer perspectives, and financial indicators[3]. In LMS the focus is always to achieve a perfect value stream for every product and process with the help of suitable tools and techniques such as JIT, 5S, TPM etc. It needs a great teamwork among all the functions throughout the supply chain. The desired result is low lead-time with fewer resources at reduced cost to provide a variety product with better quality. The waste increases the cost but not the value of product. To eliminate the waste and retain value adding activities should be done on regular basis. Waste identification is not an easy task, a proper focused approach and attention has to be provided for such activities. The continuous improvement leads to end product quality improvement, overall organizational performance, and employee's morale and customer's satisfaction. In simple terms Lean means an effective way to provide the desired products and/or services to the customers as per their need by maximum utilization of the available resources with minimum waste. So it is not surprising that many Indian Industries are looking to LMS as a manufacturing strategy to enable them to attain and sustain their competitive advantage in this global competition. As the global marketplace matures and customers redefine value, organizations find themselves in a fight for survival. Customers are demanding better products quickly at a price comparable to or lower than previously paid. Companies that cannot meet this demand will loose market place and eventually go out of business Lean means providing customers the product or service they desire when they desire it and in the most effective manner possible. Lean means maximizing the power of human resources to minimize waste to better meet customer demand. The goals of LMS are simple and straightforward; provide the best quality product, in the shortest time period possible, with the best price to the customer. [4] questioned whether the same set of tools and techniques, which are applied in Japan or USA/UK and other developing countries, will be useful in Indian context or a modification is necessary. [5] compared Lean Manufacturing in Japan and UK and found that there is a basic difference between these two countries. He stressed that Business level strategies are more important for individual organization's success and survival. Mostly the research work about Lean Manufacturing System is available for big organizations and application of its different tools and techniques at MSMEs has not been given much importance.

\subsection{Benefits of LMS}

Various authors have studied the benefits, difficulties and barriers in the implementation of LMS using empirical studies. [6] provided quantitative evidence based on the American sectoral data (for the period 1958 to 1996) that the Lean Manufacturing System and sectoral (micro) economic growth has direct relation. Copeland Corporation, a manufacturer of air conditioning and refrigeration reciprocating compressors, began adopting an adaptation of Kaizen and Lean Manufacturing in the early 1990's, since then productivity doubled and there had 
been a $33 \%$ reduction in manufacturing floor space. In addition time per unit had been reduced by $35 \%$. [7] analyzed the results of a longitudinal study of manufacturing performance,Lean Manufacturing principles and buyer supplier relationship in the Japan, UK automotive industries and US. The result reported 20\% improvement in labour productivity between 1994 and 2001 in Japanese plants where as in the US plants the productivity was same.

\subsection{Difficulties and barriers for successful Implementation of LMS [8]}

It stated that scarcity of resources is the hindrance to internationalize the small units. The main reasons for the sickness in Indian Small scale sector are little attention to technology up-gradation, quality \& productivity improvement and cost reduction in last several decades resulting in locking up of resources, wastage of capital assets, loss of production, increasing unemployment and affecting the circulation of bank credits. Their survey reported the principal causes for sickness are faulty planning, managerial deficiencies, non application of cost effective strategies, inadequate funds, inefficient financial controls, diversion of funds in unproductive purpose, inadequate attention to the $R \& D$ activities for product and process, obsolete equipments and technology, poor know how of demand forecast, quality management and project management

\subsection{Need of LMS for MSME}

Large manufacturers are implementing LMS, which affects their MSME suppliers. MSMEs can be broadly classified based on the nature of their business as under:

(1) MSME directly selling their product in the market;

(2) MSME working as an ancillary unit to one OEM;

(3) MSME working as an ancillary unit for more than one OEM;

(4) MSME catering the need of seasonal market.

Utilization of Lesser Resources is the key for LMS, but the difference lies in the fact that MSME are not using lesser resources by choice rather than they are forced to do so. This situation results in:

- Inferior services to the customers,

- More wastage at every stage due to improperly designed processes,

- High rate of rejection due to unskilled workforce,

- Old and defective machines and equipment,

- Inefficiency \& ineffectiveness due to lack of technical and managerial know-how.

- Product quality is not up to the mark.

The above diseases prove the point that it is not necessary that the organization, which uses lesser resources, is Lean and healthy but most of the times it is thin and unhealthy. MSMEs should understand the needs of customer and plan their strategies revolving around these needs.

\subsection{Industrial Engineering,Productivity and Lean}

The American Institute of Industrial Engineers defines industrial engineering as "concerned with the design, improvement and installation of integrated systems of people, materials, equipment and energy. It draws upon specialized knowledge and skill in the mathematical, physical and social sciences together with the principles and methods of engineering analysis and design to specify, predict and evaluate the results to be obtained from such systems."

Accreditation Board for Engineering and Technology defines industrial engineering as "the profession in which a knowledge of the mathematical and natural sciences gained by study, experience and practice is applied with judgment to develop ways to utilize economically, the materials and forces of nature for the benefit of mankind."

'Industrial engineer' is synonymous with systems integrator - a big-picture thinker. In other words, it's an employee who takes what exists today and conceptualizes what should exist in the future.

\subsection{The human factor is the key}

The importance of the human factor as the main determinant of sustained productivity improvement is getting to be more widely appreciated. The productivity improvement impacts of technological advance would not be fully realized without a human resource capable to exploit its potentialities and make new technologies work in a production environment. A human resource that is able to adapt the production system and work organizations to the rapidly changing technologies and markets is the foundation of long term competitiveness. In a market environment where productivity is very much dependent on innovations in products and processes and continuous improvement process, the human and social capital of the enterprise are the key to productivity and competitiveness, hence, the increasing importance of human resource management and development. 


\subsection{Work measurement study}

The Work Measurement study at all the Units will be done by the consultants of UMAS along with the core team in the Division. This study will include generating the element details for activities based on the inputs gathered by the consultants through video shooting and the information collected by the core team. Based on the requirements of the processes and activities, sub-operations will be developed and the same will be used for creating Operations, Part Routing and Product Routing in MDAT. UMAS team also complete the Product Routing for the jobs products manufactured in a particular Unit.

\subsection{The concept of MOST[9]}

III. Methodology

The desire to know how long it should take to perform work must surely have been present in those individuals responsible for erecting ancient monuments or shaping tools. Why $\mathrm{d}$ id the ancients and why do we need to be able to predict with accuracy the length of a working cycle? How was such a prediction made? How is it made now? There are many reasons for wanting to know the amount of time a particular task should take to be completed. It may simply be for reasons of curiosity. But realistically, it is for any of three reasons:

(1) to accomplish planning,

(2) determine performance and

(3) establish costs.

Suppose an organization wishes to manufacture a new product.Knowing how much time it takes to perform certain tasks enables a manager to achieve and maintain a high utilization of personnel, material and equipment. This results in an overall efficiency that will make sustainable organizational growth possible.

The first predetermined motion time system placed in the public domain, Methods Time Measurement (MTM), was developed in 1948 by Harold B. Maynard, G. J. Stegemerten and J. L. Schwab. Because it is a very detailed system, MTM has been recognized as a very accurate predetermined motion time system. It is also widely accepted. The MTM system has a detailed data card of basic motions (reach; move; grasp; position; release; body, leg and foot motions, each associated with particular variables. Basic motions are identified, the variables are considered and the appropriate times are chosen from the data card. Because of its detail, MTM can be a very exact system, but also very slow to apply. Basic motion distances must be accurately measured in inches or centimeters and correctly classified. Because of the detail level needed with MTM, analyst errors can be a problem. The time that result from performing MTM analysis reflects a 100\% performance level and can be established for operations prior to their execution..

Based on a new concept conceived in 1967, BasicMOST for general industrial applications was developed and introduced in 1972 in Sweden and in 1974 in the United States. Since the 1970s, BasicMOST has been applied in manufacturing, service and distribution industries. While BasicMOST is the most widely used system, MOST Systems was expanded in 1980 to include MiniMOST and Maxi-MOST. MiniMOST was developed to give work measurement applicators a choice in measuring work for short cycle, highly repetitive operations. MTM was the predominant system for these activities, but as stated above, too cumbersome and detailed to easily apply. MiniMOST is a simpler system, but still able to provide a high level of accuracy and consistency. On the other spectrum, BasicMOST was considered too detailed for industries with long cycle operations. MaxiMOST began in the shipbuilding industry and has expanded to maintenance and heavy assembly operations. Rounding out the MOST Systems is ClericalMOST Originally developed in the 1970s, ClericalMOST was designed for the clerical activities in office and service environments. ClericalMOST has been updated to reflectcurrent administrative tasks and is now called AdminMOST Since the inception of the MOST Work Measurement Technique, more than 40,000 individuals worldwide, primarily industrial engineers, have been trained and certified as MOST applicators.

\subsection{Basic MOST}

Three activity sequences are needed in BasicMOST for describing manual work, and a fourth is used for measuring the movements of objects with manual cranes.

- The General Move Sequence Model is used for the spatial movement of an object freely through the air.

- The Controlled Move Sequence Model is used for the movement of an object when it remains in contact with a surface or is attached to another object during the movement (e.g., the movement of the object is controlled).

- The Tool Use Sequence Model is used for the use of common hand tools. 


\subsection{Time Unit}

The time units used in MOST are identical to those used in the basic MTM system and are based on hours and parts of hours called Time Measurement Units (TMU). One TMU is equivalent to 0.00001 hour. The following

conversion table is provided for calculating standard times:

$1 \mathrm{TMU}=0.00001$ hour 1 hour $=100,000 \mathrm{TMU}$

$1 \mathrm{TMU}=0.0006$ minute 1 minute $=1667 \mathrm{TMU}$

$1 \mathrm{TMU}=\mathbf{0 . 0 3 6}$ second 1 second $=\mathbf{2 7 . 8} \mathrm{TMU}$

\subsection{General Rules for Using MOST}

-Each sequence model is fixed.

-No letter may be added or omitted for the General or Controlled Move Sequence.

-No letter may be added or omitted for the Tool Use Sequence, with a few exceptions.

The purpose of the MOST system is to calculate the cycle time for an operation based on Pre-determined time study data A typical MOST work sequence code would look like this:An example

\section{A10 B6 G3 A6 P3 A0}

Step 1

add up all the subscript numbers

$10+6+3+6+3+0=28$ (the subscript is the MOST index value)

Step 2

Multiple the sum of the index by 10

This answer gives the TMU equivalent

$28 \times 10=280 \mathrm{TMU}$

Step 3

Convert to time

$280 \mathrm{TMU} * .036$ seconds $=10.08$ seconds

\subsubsection{General Move Sequence}

The sequence is - A B G A B P A

\begin{tabular}{|c|c|c|c|c|c|c|}
\hline \multicolumn{7}{|c|}{ General move index values } \\
\hline $\begin{array}{l}\text { A(Action } \\
\text { distance)- }\end{array}$ & $\begin{array}{l}<5 \mathrm{c} \\
\mathrm{ms}\end{array}$ & With in reach & $1-2$ steps & $3-4$ steps & $\begin{array}{l}5-7 \\
\text { steps }\end{array}$ & 8-12 steps \\
\hline $\begin{array}{l}\mathrm{B}(\text { Body } \\
\text { motion) }\end{array}$ & & & Bend and Arise & & $\begin{array}{l}\text { Sit or } \\
\text { stand }\end{array}$ & $\begin{array}{l}\text { Through } \\
\text { door,Climb } \\
\text {,on,off }\end{array}$ \\
\hline $\begin{array}{l}\text { G(Gain } \\
\text { control) }\end{array}$ & & Light object & $\begin{array}{l}\text { Heavy or bulky,Blind or } \\
\text { Obstructed,Disengaged } \\
\text {,Interlocked }\end{array}$ & & & \\
\hline $\begin{array}{l}\text { P(Placem } \\
\text { ent) }\end{array}$ & Hold & $\begin{array}{l}\text { Lay aside } \\
\text {,Loose fit }\end{array}$ & Adjustments,Light pressure & $\begin{array}{l}\text { Care,precision, } \\
\text { Heavy pressure }\end{array}$ & & \\
\hline $\begin{array}{l}\text { Index } \\
\text { value }\end{array}$ & 0 & 1 & 3 & 6 & 10 & 16 \\
\hline
\end{tabular}

Four sub activities constitute the General Move Sequence

A - Action Distance (mainly horizontal)

B - Body Motion (mainly vertical)

$\mathrm{G}$ - Gain Control

$\mathrm{P} \quad$ - Placement

The General Move follows a fixed sequence of steps:

-Reach, either directly or in conjunction with body motions or steps.

-Gain control of the object.

-Move the object, as in "reach".

-Place the object in temporary or final position.

-Return to the workplace.

General Move Example

From a stack located 10 feet away, a heavy object must be picked up and moved 5 feet and placed on top of a workbench with some adjustments.

\subsubsection{Controlled Move Sequence}

The sequence is -A B G M X I A 
Three new sub activities are found in the Controlled Move Sequence

M - Move Controlled

$\mathrm{X}$ - Process Times

I - Alignment

The Controlled Move Sequence describes the manual displacement of an object over a "controlled" path. The Controlled Move follows a fixed sequence of steps:

Reach, either directly or in conjunction with body motions or steps.

Gain control of the object

Move the object over a controlled path.

Allow time for the process to occur.

Align the object after the move/process.

Return to the workplace.

A Controlled Move is performed under the following conditions:

- The object or device is restrained by its attachment to another object

- It's controlled during the move by the contact it makes with the surface of another object.

- It must be moved on a controlled path to accomplish the activity.

- Move Controlled (M)

- This parameter is used to analyze all manually guided movements or actions of an object over a controlled path.

- Controlled Move Example

- From a position in front of a lathe, the operator takes two steps to the side, turns the handwheel two rotations, and sets the cutting tool by aligning the handwheel dial to a scale mark.

\subsubsection{The Tool Use Sequence}

The sequence is - A B G A B P - A B P A

It is a combination of the General Move and Controlled Move activities.Tools not listed in the tables that are similar to a tool in the table can use their time values for analysis.

Tool Use Phases

-Get Tool (Object)

-Put Tool (Object) in Place

-Use Tool

-Put Tool (Object) Aside

-Return

The Tool Use Sequence model makes use of the "A", "B", "G", and "P" parameters, which are all familiar to us, plus the new Tool Use parameters. Tool Use Sequence Parameters are given below placed at- shown in sequence.

$\mathrm{F}$-- Fasten

L -- Loosen

C -- Cut

S -- Surface Treat

$\mathrm{M}$-- Measure

$\mathrm{R}$-- Record

T - Think

\section{Case study}

The company in which I started my project work is Gurunanak engineering works ingaged in small and medium mechanical maintenance work on order of small and medium scale industries.Productivity improvement exercises were earlier done in this industry[9].

Using MOST application lean cycle time(CT) and work content $(\mathrm{CW})$ of each operation are calculated.During the maintenance of a gate valve,operation of cleaning up the part on milling machine .I studied and prepare a complete sequence of operations and actual time consumed and compare it with time by using MOST technique. Some definitions are as follows

Work content $=$ Operator time $=$ On Line + Off Line + Move

Cycle time $=$ Operation time $=$ On Line + Auto cycle

On line time $=$ Time of manual activities done by operator when machine is not running.

$=$ Longest $/$ Critical path time of activities done in parallel.

Off line time $=$ Time of manual activities done by operator when machine is running.

$=$ SUM of time of activities done in parallel.

Move $=$ Walking time of operator from work center to next work center in multi machine /stageworking. 
4.1 Observation Table - Time Sheet

Operation-Milling to clean up the valve body-

\begin{tabular}{|c|c|c|c|c|c|c|c|}
\hline $\begin{array}{l}\text { Operati } \\
\text { on No }\end{array}$ & $\begin{array}{l}\text { Operation/Sub } \\
\text { Operation/Method Description }\end{array}$ & Freq & Men & $\begin{array}{l}\text { CT } \\
\text { (Min) }\end{array}$ & $\begin{array}{l}\text { CW } \\
\text { (Min) }\end{array}$ & $\begin{array}{l}\text { LeanCT } \\
\text { (Min) }\end{array}$ & $\begin{array}{l}\text { LeanCW } \\
\text { ( Min) }\end{array}$ \\
\hline 1 & Collection of crane and pendant & 1 & 1 & 2.6 & 2.6 & 0.72 & 0.72 \\
\hline 2 & $\begin{array}{l}\text { Horizontal travel of empty } \\
\text { crane }\end{array}$ & 2 & 1 & 20.1 & 20.1 & 3.60 & 3.60 \\
\hline 3 & Working of job with sling & 1 & 1 & 10.0 & 10.0 & 5.40 & 5.40 \\
\hline 4 & $\begin{array}{l}\text { Upward travel of crane with } \\
\text { gate valve (for } 1 \text { meter) }\end{array}$ & 1 & 1 & 12.6 & 12.6 & 12.48 & 12.48 \\
\hline 5 & $\begin{array}{l}\text { Horizontal travel of loaded } \\
\text { crane towards machine }\end{array}$ & 2 & 1 & 20.1 & 20.1 & 3.6 & 3.6 \\
\hline 6 & $\begin{array}{l}\text { Downward travel of loaded } \\
\text { crane (for } 1 \text { meter) }\end{array}$ & 1 & 1 & 12.6 & 12.6 & 12.48 & 12.48 \\
\hline 7 & $\begin{array}{l}\text { Push/Pull component while } \\
\text { resting on fixture }\end{array}$ & 2 & 1 & 2.2 & 2.2 & 2.16 & 2.16 \\
\hline 8 & Unhooking of job with sling & 1 & 1 & 8.2 & 8.2 & 3.24 & 3.24 \\
\hline 9 & $\begin{array}{l}\text { Horizontal travel of empty } \\
\text { crane to aside it }\end{array}$ & 2 & 1 & 20.1 & 20.1 & 3.6 & 3.60 \\
\hline 10 & $\begin{array}{l}\text { Clamping of component side } \\
\text { clamp with }\end{array}$ & 1 & 1 & 19.8 & 19.8 & 8.28 & 8.28 \\
\hline 11 & $\begin{array}{l}\text { Clamping of component side } \\
\text { clamp }\end{array}$ & 1 & 1 & 18.4 & 18.4 & 6.84 & 6.84 \\
\hline 12 & $\begin{array}{l}\text { Operate the levers to start the } \\
\text { machine }\end{array}$ & 3 & 1 & 5.4 & 5.4 & 3.24 & 3.24 \\
\hline 13 & Process time for operation & 103 & 1 & 103.0 & 103.0 & 103.0 & 103.0 \\
\hline 14 & $\begin{array}{l}\text { Declamping of component side } \\
\text { clamp }\end{array}$ & 1 & 1 & 18.7 & 18.7 & 7.92 & 7.92 \\
\hline 15 & $\begin{array}{c}\text { Declamping of component side } \\
\text { clamp }\end{array}$ & 1 & 1 & 18.0 & 18.0 & 7.2 & 7.2 \\
\hline 16 & Collection of crane and pendant & 1 & 1 & 2.5 & 2.5 & 0.72 & 0.72 \\
\hline 17 & $\begin{array}{l}\text { Horizontal travel of empty } \\
\text { crane }\end{array}$ & 2 & 1 & 20.2 & 20.2 & 3.60 & 3.60 \\
\hline 18 & Hooking of job with sling & 1 & 1 & 10 & 10 & 5.4 & 5.4 \\
\hline 19 & $\begin{array}{l}\text { Upward travel of crane with } \\
\text { gate valve }\end{array}$ & 1 & 1 & 12.6 & 12.6 & 12.48 & 12.48 \\
\hline 20 & $\begin{array}{l}\text { Horizontal travel of loaded } \\
\text { crane towards pallet }\end{array}$ & 2 & 1 & 20.2 & 20.2 & 3.6 & 3.6 \\
\hline 21 & $\begin{array}{c}\text { Downward travel of loaded } \\
\text { crane }\end{array}$ & 1 & 1 & 12.6 & 12.46 & 12.48 & 12.48 \\
\hline 22 & $\begin{array}{l}\text { Push/pull component while } \\
\text { resting on pallet }\end{array}$ & 2 & 1 & 2.2 & 2.2 & 2.16 & 2.16 \\
\hline 23 & Unhooking of job with sling & 1 & 1 & 8.2 & 8.2 & 3.24 & 3.24 \\
\hline 24 & $\begin{array}{l}\text { Horizontal travel of empty } \\
\text { crane to aside it }\end{array}$ & 2 & 1 & 20.1 & 20.1 & 3.6 & 3.6 \\
\hline
\end{tabular}




\subsection{Result Table}

\begin{tabular}{|c|c|c|c|c|c|}
\hline $\begin{array}{c}\text { Operation } \\
\text { No. }\end{array}$ & Operation & $\begin{array}{l}\text { CT } \\
\text { (Min) }\end{array}$ & $\begin{array}{l}\text { CW } \\
\text { (Min) }\end{array}$ & $\begin{array}{l}\text { Lean CT } \\
\text { (Min) }\end{array}$ & $\begin{array}{l}\text { Lean CW } \\
\text { (Min) }\end{array}$ \\
\hline 01 & Milling to clean up the part & 400.4 & 400.4 & 231 & 231 \\
\hline
\end{tabular}

\section{Calculation}

Actual Productivity $=1 / 400.4 \times 100=0.2497$

Lean Productivity $=1 / 231 \times 100=0.4329$

Lean productivity-Actual productivity

Percentage increase in productivity $=$ Actual productivity

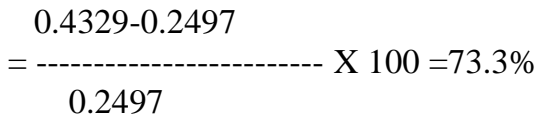

\section{Conclusion}

Lean Manufacturing is an operational strategy oriented toward achieving the shortest possible cycle time by eliminating waste. It is derived from the Toyota Production System and its key thrust is to increase the value added work by eliminating waste and reducing incidental work. The technique often decreases the time between a customer order and shipment, and it is designed to radically improve profitability, customer satisfaction, throughput time, and employee morale. The benefits generally are lower costs, higher quality,and shorter lead times. "Productivity is being better today than yesterday, and that tomorrow will be better than today..." The concept of what is better and how to become better is changing.

By the implementation of basic MOST technique in the two case studies, we see that there are good percentage increase in work force productivity.There are complete elimination of human work waste results large saving in production cost so it is a lean production.

\section{REFERENCES}

[1] Katayama, H. and Bannett, D. (1996). Lean production in a changing competitive world: a Japanese perspective. Int. Journal of Operations \& Production Management, 16(2):8- 23.

[2] Varamaki, E., Kohtamaki, M., and et al. (2008). A framework for a network-level performance measurement system in SME networks. International Journal of Networking and Virtual Organisations, 5(3-4):415-435.

[3] Womack, J., Jones, D., and Roos, D. (1990). The Machine that changed the world. Rawson Associates, New York.

[4] Garg, S., Vrat, P., and Kanda, A. (1994). Work Culture in JIT environment. Productivity, 35(4):463-466.

[5] Pilkington, A. (1998). Manufacturing strategy regained evidence for the best practice. California Management Review, 41:31-42.

[6] Sanidas, E. (2000). The successful imitation of the Japanese lean production system by American firms: Impact on American growth. In ESRC Center for Business Research.

[7] Oliver, N., Delbridge, R., and Barton, H. (2002). Lean production and Manufacturing performance improvement in Japan, the UK and US 1994-2001. Business Research. ESRC Centre for Business research. www.netec.mcc.ac.uk/ WoPEc/data/Papers.

[8] Moen, O. (1999). The relationship between firm size, competitive advantages and export performance revisited. International Small Business Journal, 18:53-72.

[9] UMAS Engineering consultant firm ebookbrowse.com 